\title{
SOBREVIVENTES DE CÂNCER INFANTO-JUVENIL EM TEIXEIRA DE FREITAS: VICISSITUDES NA VIDA ADULTA
}

\author{
AUTOR: MURILO SOUSA RAMOS \\ CO-AUTOR: BEATRIZ RIHS MATOS TAVARES \\ CO-AUTOR/ORIENTADOR: MILENA DOREA DE ALMEIDA
}

Resumo: $\mathrm{O}$ termo sobrevivente é uma referência à palavra inglesa survival e, em estudos internacionais e nacionais, há uma diversidade de critérios para delimitar o período para ser considerado sobreviventes de câncer infantojuvenil (SCAIJ) e quando esse tempo começa a ser contado, se no diagnóstico ou no final do tratamento. Atualmente, as equipes brasileiras que tratam de SCAIJ inserem em sua lista pacientes fora de tratamento oncológico há pelo menos dois anos. Por isso, este presente plano de trabalho teve como objetivo investigar os sentidos e significados que adultos, SCAIJ, residentes em Teixeira de Freitas/BA têm da doença, de seu tratamento e de suas experiências de vida durante o adoecimento e após o término do tratamento oncológico. Contudo, para contemplar os objetivos do estudo, os procedimentos metodológicos foram readequados devido a situação pandêmica do Coronavírus. As entrevistas com o público-alvo não puderam ser realizadas e se elaborou uma pesquisa de revisão integrativa na literatura sobre as perspectivas das publicações brasileiras no período de 2000-2020 cujo tema sejam sobreviventes de câncer infantojuvenil. Ao aplicar os critérios de inclusão e exclusão, foram selecionados 21 artigos para o banco de dados da pesquisa e ao traçar o panorama desses estudos, realizou-se a seguinte divisão temática: efeitos tardios físicos, psicossociais e subjetivos. Compreende-se que as sequelas oncológicas são complicações ou lesões que decorrem do câncer e os efeitos tardios são insidiosos no início, ocorrem fora da faixa etária pediátrica e contribuem para prematuras morbimortalidade. Considerando as sequelas e os efeitos tardios físico, destaca-se: repercussão cardiovasculares, metabólicas, déficits no desenvolvimento físico e cognitivo, e até mesmo segundas neoplasias. Verifica-se que as condições clínicas do início do tratamento, as características do tratamento, a idade no diagnóstico, a genética do paciente influenciam diretamente em seus efeitos tardios. Finaliza-se destacando a importância de mais pesquisas nacionais que investiguem, de forma interdisciplinar e multicêntrica, os efeitos tardios da doença e do tratamento oncológico, relacionando-os a multifatorialidade, como aspectos do adoecimento, físicos, genéticos, cultural, social, psíquicos. Assim, será possível elaborar tratamentos curativos com qualidade de vida.

Palavras-chave: Câncer em crianças, Sobreviventes de Câncer, Sequelas, Efeitos Tardios. 